\title{
“A VIDA NÃO É FÁCIL, A MINHA TAMBÉM NÃO FOI. MAS VALEU ATÉ AQUI" Entrevista com o professor Geraldo Alves de Souza
}

\author{
Cristiano da Silva Paiva \\ Doutorando pela Universidade Federal de Santa Catarina - UFSC \\ cristianopaiva1@hotmail.com
}

\section{APRESENTAÇÃO \\ Um breve histórico do entrevistado}

Esta entrevista ocorreu com o professor doutor Geraldo Alves de Souza em dezembro de 2021, de forma remota, e é uma singela homenagem à sua aposentadoria do Departamento de Geografia da Universidade Federal do Amazonas. O professor Geraldo Alves, nasceu em 27 de janeiro de 1959. É filho de José Alves Ferreira e Fernandina de Souza Ferreira. É casado com Cynthia Patrícia Bindá Alves há 24 anos, tendo dois filhos, Arthur Bindá Alves e Eduarda Bindá Alves.

Iniciou sua trajetória acadêmica graduando-se em Geografia pela Universidade Federal de Uberlândia - UFU em 1989. Fez o mestrado em Geografia pela Universidade Estadual Paulista Júlio de Mesquita Filho - UNESP em 2001, sendo orientado pelo professor doutor Ailton Luchiari, e recebeu o grau de doutor pelo Programa de Engenharia de Transportes - PET/COPPE da Universidade Federal do Rio de Janeiro - UFRJ no ano de 2009 com a tese intitulada "Espacialidade urbana, circulação e acidentes de trânsito: o caso de Manaus, AM (2000 a 2006)" orientada pelo professor doutor Carlos David Nassi.

Seu percurso na docência universitária iniciou pela Faculdade de Educação Ciências e Letras de Iporá - FECLI em 1991, onde foi contratado para ministrar disciplinas de Geografia. No ano de 1993 prestou concurso e foi aprovado para professor do Departamento de Geografia da Universidade Federal do Amazonas - UFAM onde esteve vinculado por 28 anos, até 2021. Também teve atuando no Sistema de Proteção da Amazônia - SIPAM, entre 2004 e 2008, cedido pela UFAM para realização de atividades técnicas no referido órgão.

Na UFAM foi professor das disciplinas de Cartografia Básica, Cartografia Temática, Fundamentos Teóricos e Metodológicos da Geografia, Geografia da Circulação, Geografia Econômica, Geografia Humana, Geografia Regional, Geotecnologias e ensino de Geografia, Introdução ao Sensoriamento Remoto, Processamento de Informação Geográfica I, Processamento de Informação Geográfica II e Geografia Urbana.

Desde 2010 atua como avaliador institucional pelo Instituto Nacional de Estudos e Pesquisas Educacionais Anísio Teixeira, INEP/MEC e, atualmente, é professor do 
Programa de Pós-Graduação em Geografia - PPGEOG, na UFAM e coordenador do Núcleo de Estudos e Pesquisas das Cidades da Amazônia - NEPECAB, cujo objetivo é compreender e analisar problemáticas socioespaciais das cidades da Amazônia por diferentes perspectivas.

Seus projetos e pesquisas são dedicados aos seguintes temas: geoprocessamento, transporte, mobilidade e acessibilidade de populações urbanas. A produção bibliográfica do professor Geraldo Alves em periódicos perpassa por colaborações com seus orientandos de iniciação cientifica, mestrado e doutorado. Mas também, desfruta de importantes reflexões individuas à exemplo do artigo "Produção do espaço e mobilidade urbana: na contramão da sustentabilidade" e o texto "Transporte Púbico a preço único: reforçando as desigualdades sociais", no qual aborda visões bastante complexas a respeito do debate sobre mobilidade urbana e financiamento de transportes no Brasil. Os debates promovidos pelo artigo, são um contraponto à ideia comumente aceita no Brasil a respeito da adoção de um valor único para a tarifa do transporte coletivo urbano. Esta teria por finalidade promover a justiça social - porque tradicionalmente, a periferia tem sido ocupada pela população de baixo rendimento e tarifas diferenciadas de acordo com a distância das viagens elevariam as despesas com transportes de uma população já socialmente penalizada. Esta prática seria "uma forma ardilosa de levar a população pobre para a periferia da cidade e, ao livrar-se dela, a sociedade burguesa evita que os recursos destinados às classes média e alta sejam divididos com esta população".

Além destes, em parceria com o professor José Aldemir de Oliveira, foi organizador da primeira edição do livro "Geografia da saúde: ambientes e sujeitos sociais no mundo globalizado", e também possui oito capítulos de livros publicados sobre as temáticas de trânsito, segurança e analises espaciais.

É coordenador do projeto de extensão denominado "Seminários NEPECAB", realizado mensalmente desde 2016 com o intuito de debater temáticas relacionadas à urbanização na Amazônia e áreas afins. Esta atividade conta com o envolvimento de outros professores, tais como Tatiana Schor e Paola Verri de Santana e de diversos estudantes de graduação e de pós-graduação entre mestrado e doutorado.

\section{ENTREVISTA}

C: CRISTIANO PAIVA

G: GERALDO ALVES

C: Professor, nos conte um pouco sobre suas origens, local de nascimento, cidades onde já morou, histórico familiar, lembranças e vivências da juventude. 
G: Sou filho de agricultores. Nasci em 1959 e cresci na zona rural do município de Iturama, município que fica no pontal do Triângulo Mineiro. Vivi e trabalhei na roça até os meus 18 anos de idade. Ainda pequeno a gente começa a aprender como trabalhar, ajudando os adultos em diferentes tarefas, servindo para buscar um animal no pasto, apartar o gado, dar comida aos porcos e, na medida em que a gente vai crescendo, vamos assumindo outras tarefas mais pesadas. Trabalhei na roça plantando arroz e milho no primeiro momento e depois algodão.

Quando eu era criança, a região ainda era toda tomada de mata - o cerradão - mas na geração dos meus pais teve início o processo de retirada da floresta para a formação de lavouras e pastagens. Naquela época (década de 1960) o Banco do Brasil de Fernandópolis - São Paulo - passou a financiar o processo de desmatamento das propriedades. Então, quase todos os proprietários rurais da região contraíram empréstimos para comprar máquinas e equipamentos para retirada da floresta e beneficiar a terra: tratores, arados, grades, máquinas de plantação e colheita para mecanizar a produção agrícola.

Meus pais, com menor propriedade, não compraram máquinas e equipamentos. Quando era necessário arar a terra, contratavam os outros proprietários rurais que tinham esses equipamentos. Foi assim a minha infância e juventude na zona rural: plantar, beneficiar e colher (quase sempre) com resultados muito modestos. A vida era dura.

Meus irmãos mais velhos ao completar maioridade casaram-se e não conseguiram prosseguir com os estudos. Os meus pais continuaram com a propriedade rural até o fim de suas vidas, na década de 1980. Nós - os filhos - permanecemos com a propriedade até recentemente, quando foi finalmente repassada a terceiros.

Eu cursei o primário numa escola rural construída próxima à propriedade dos meus pais e fui o único dos seis filhos que saiu para estudar na cidade. Fui para a sede do município (Iturama) em 1977 para cursar a quinta série do ginásio (atual sexto ano do ensino fundamental). Lá estudei até 1980, quando concluí a oitava série; o nível ginasial. No ano seguinte me mudei para Uberlândia - cidade que oferecia maiores oportunidades de trabalho - com o abjetivo de cursar o colegial.

Talvez um aspecto importante a ser destacado é que, a partir desse processo de desmatamento houve uma grande imigração de famílias vindas de outros estados (principalmente de São Paulo) para cultivar a terra nessa região. Então formaram-se pequenos aglomerados nas fazendas. As casas eram construídas precariamente para abrigar esses trabalhadores: o piso era de chão batido e as paredes de taipa. Em 1969 fundou-se uma cidade, formada a partir desta leva de imigrantes para região. Hoje é o município de Limeira do Oeste com mais de vinte mil habitantes.

Alguns anos depois notou-se um processo de emigração dessas mesmas famílias para o sul de Goiás, ou para a área central e norte do estado de Mato Grosso - a nova frente de penetração da fronteira agrícola que tinha atravessado o Triângulo Mineiro e que agora atingia estes estados. 
A partir do momento em que a terra foi perdendo a fertilidade típica da floresta, a região foi sendo convertida em bacia leiteira, trocando a lavoura pela pecuária. Grandes laticínios foram construídos na região e era comum dezenas de caminhões indo para as fazendas buscar leite nas propriedades rurais. Esta atividade econômica durou algumas décadas e foi, aos poucos, substituída pela cana-deaçúcar, que atualmente ocupa boa parte da região - processo ainda em curso. Atualmente há quatro grandes usinas que produzem açúcar e álcool na região: uma no município de Iturama, outra em Carneirinho, outra em Limeira do Oeste e outra em Santa Vitória - todas nos vales dos rios Grande e Paranaíba.

\section{C: Quais os caminhos iniciais que o levaram à Geografia e à docência no Ensino Superior?}

G: Em Iturama fui estudar à noite porque meus pais não tinham condições de pagar as minhas despesas. Estudava à noite e trabalhava durante o dia. O melhor emprego que tive nesta época foi nas Casas Pernambucanas onde iniciei como auxiliar de crédito e cobrança.

Como já mencionado, em 1981 me mudei para Uberlândia com a intenção de continuar trabalhando e cursar o ensino médio. Como trabalhar e estudar se tornou muito difícil, abandonei o primeiro colegial. Foi então que iniciei o supletivo do ensino médio, fazendo provas em Minas Gerais e Goiás para eliminar as matérias. Conclui o supletivo em 1982.

Em Uberlândia o melhor emprego foi na empresa Spirandelli - lojas de móveis e eletrodomésticos. Comecei como chefe de crédito e cobrança e cheguei ao cargo de gerente de loja.

No início de 1983, sem muitas perspectivas de crescimento profissional, decidi me mudar para Curitiba com a intenção de continuar trabalhando e fazer cursinho para entrar no curso superior na Universidade Federal do Paraná. Trabalhava durante o dia e fazia cursinho à noite. O que ganhava não era o suficiente para me manter lá e em outubro voltei para a zona rural, para casa dos meus pais.

No início de 1984 voltei à Curitiba para fazer o vestibular, mas não fui aprovado. Nesse mesmo início de ano fui aprovado para Estudos Sociais no vestibular de uma faculdade particular, o que me levou de volta para Uberlândia. Comecei a estudar e consegui emprego no Bradesco.

No meio do ano passei para Estudos Sociais na Universidade Federal de Uberlândia - UFU. A separação entre Geografia e História me permitiu no início de 1985 fazer opção pela licenciatura plena em Geografia - curso que concluí em 1988.

Durante minha graduação trabalhei no Bradesco até março de 1987. Depois tive outros empregos e comprei um bar - sempre dando um jeito para sobreviver e concluir a graduação. Vendi o boteco e fiquei meio sem o que fazer, até aparecer a oportunidade de substituir, por um mês, um professor de geografia da escola 
estadual Izoldino Soares de Freitas, em Limeira do Oeste no mês de novembro de 1989. Este professor tomou a iniciativa de continuar afastado da escola, o que permitiu que eu continuasse com o contrato.

Nas férias de julho eu fui à Uberlândia e procurei o Departamento de Geografia para conseguir documentários sobre conteúdos de Geografia em fitas VHS para levar para projetar nas salas de aulas. Foi quando o professor Roberto Rosa me informou que estavam precisando de professores na Faculdade de Ciências e Letras de Iporá - FECLIP - em Iporá, Goiás. Entrei em contato com o diretor da faculdade e fui contratado.

Deixei as aulas dos ensinos fundamental e médio e me mudei para Iporá para dar aula no ensino superior - algo que desejava muito. Permaneci lá até início de 1993 quando tomei conhecimento do concurso público no Departamento de Geografia da UFAM através do professor Vitor Ribeiro Filho. Na época eu tinha apenas a graduação, mas mesmo assim tomei a iniciativa de vir fazer o concurso. Fui aprovado. Tomei posse em maio de 1993 e trabalhei até junho de 2021, quando me aposentei.

Em 1998 fui autorizado pelo departamento a me afastar para fazer o mestrado na UNESP de Rio Claro, São Paulo. Defendi a dissertação e voltei para a sala de aulas em 2001.

Em 2004 fui cedido ao Sistema de Proteção da Amazônia - SIPAM, onde permaneci até abril de 2008. Em 2005 tive oportunidade de iniciar o meu doutoramento no Programa de Engenharia de transportes - PET/COPPE da Universidade Federal do Rio de Janeiro - UFRJ, tendo defendido a tese em março de 2009.

\section{C: Qual a sua memória da Geografia da época de estudante do ensino básico e superior? Houve algum professor marcante em algum período?}

G: Um professor da escola rural - José Carlos - levou para sala de aulas um livro de Geografia que tinha algumas ilustrações sobre o sistema solar. Ao folheá-lo, aquelas figuras me chamaram a atenção. Me interessei pelo livro e o professor me emprestou-o por algumas semanas. Acho que foi este fato que despertou meu interesse pela Geografia. Eu gostei demais da parte da Astronomia. Acho que foi aí que começou a minha vocação pela área da geografia.

\section{C: Sua formação inicial na Geografia resultou em mudanças na forma de pensar, ou em alguma prática social?}

G: Como destacado acima, minha graduação foi cursada na segunda metade da década de 1980, momento em que ganhava espaço no Brasil a corrente do pensamento geográfico denominada de Geografia Crítica, principalmente a partir do Encontro Nacional de Geógrafos em Fortaleza, no ano de 1978. 
Quase todos os professores do Departamento de Geografia da UFU tiveram seu processo de qualificação (mestrado e doutorado) cursado na Geografia da USP, principal berço da Geografia Crítica. Desse modo, a leitura que predominava na graduação era este conteúdo de natureza crítica e isso teve forte influência na minha maneira de ver o mundo.

Durante a minha graduação o ensino superior no Brasil passava por crises, com ameaças de privatização das universidades federais, falta de ajustes nos salários dos servidores, entre outras questões que provocaram a reação da comunidade acadêmica. Era comum a ocorrência de greves e passeatas pelas principais ruas de Uberlândia, além de assembleias em ginásios lotados, discutindo aspectos da educação e da sociedade brasileira. Como estudante me envolvi diretamente com esses movimentos a ponto de (ao me juntar a outros bancários), liderar uma greve do setor bancário no início do ano de 1987 - o que me custou o emprego que tinha no Bradesco.

\section{C: Ainda sobre sua trajetória inicial na Geografia, quais foram as mudanças que ocorreram ao longo do tempo na Epistemologia da Geografia, para a que pratica contemporaneamente?}

G: Eu acho que a principal mudança foi o esforço empreendido para suprimir a Geografia Quantitativa a partir do crescimento da Geografia Crítica. Me lembro que durante a minha graduação eram grandes as críticas à Geografia Tradicional e à Quantitativa, cujo principal centro era o curso de Geografia da UNESP de Rio Claro.

As principais mudanças que acompanhei mais diretamente foram o crescimento da corrente da Geografia Crítica e o emprego do geoprocessamento, sensoriamento remoto, Sistemas de Informações Geográfica - SIG - e geotecnologias nos estudos de geografia dos anos mais recentes. Uma revalorização dos dados para os estudos geográficos.

\section{C: Entre a sua graduação e a pós-graduação houve um período de interstício? O que lhe levou a retornar e avançar nos estudos em Geografia, a nível de mestrado e doutorado?}

G: Penso que retomar os estudos de geografia somente foi possível em função da minha ocupação. Como professor do ensino superior das universidades federais, o plano de carreira permite o afastamento para cursar mestrado e doutorado e foi isso, seguramente, o que me levou a retomar a minha formação.

Como já destacado, ingressei no Departamento de Geografia da UFAM apenas com a graduação. Somente depois de ter cumprido o estágio probatório e aguardado o retorno de alguns colegas voltando do mestrado é que fui autorizado a sair para cursar o mestrado. 
O doutorado também teria seguido o mesmo rito, mas como estava cedido ao SIPAM e o curso e doutorado foi oferecido interinstitucional (convênio entre a Faculdade de Tecnologia - FT/UFAM e a COPPE/UFRJ), tive a oportunidade de cursar as disciplinas em Manaus, e ir para o Rio de Janeiro apenas para orientações e as defesas de qualificação e da tese doutorado, o que facilitou muito a minha qualificação a nível de doutorado.

\section{C: Atualmente há muitas dificuldades para a pós-graduação e o financiamento de pesquisas na Geografia. Qual era a realidade naquele momento para o desenvolvimento e incentivo de estudos em nível superior?}

G: Ao término da minha graduação, a quantidade de vagas oferecidas para a pósgraduação em Geografia no Brasil era infinitamente inferior ao que temos atualmente, o que restringia possibilidade de dar continuidade aos estudos. Boa parte dos que seguiam para o mestrado e doutorado eram professores dos cursos superiores das universidades públicas e privadas do país. Mais recentemente cresceu bastante a oferta de cursos e de vagas nos níveis de mestrado e doutorado em Geografia no Brasil, assim como cresceu também a oferta de bolsas de estudo, apesar das dificuldades dos últimos anos.

C: Em relação à sua admissão aqui na Universidade Federal do Amazonas (UFAM) para o cargo de professor. Como foi sua chegada ao Amazonas, e atuação nos primeiros anos no Departamento de Geografia da UFAM?

G: Como já destacado, tomei posse em maio de 1993 já com disciplinas lotadas para mim, tendo que correr com elas para encerrar dentro do período letivo. Comecei trabalhando com Geografia Agrária e geografia humana e econômica. Esta oferecida para o curso de Ciências Sociais. Fui bem recebido. Meus colegas me apoiaram bastante. Na época tínhamos uma turma em Parintins e foi muito rico o processo de aprendizado com a experiência de ir para o interior do Estado no momento das férias do curso da sede.

$\mathrm{Na}$ época o Departamento de Geografia era muito pequeno e a gente se desdobrava, assumindo uma carga bastante pesada de disciplinas para liberar os colegas para sair para o mestrado e na medida em que estes iam voltando outros eram autorizados a sair, sempre revezando entre quem ficava sobrecarregado de disciplinas e outros que estavam liberados para a pós-graduação.

O Departamento de Geografia oferecia apenas a licenciatura no turno matutino, com a possibilidade de fazer complemento de habilitação para concluir também o bacharelado. Salvo engano foi a partir da grade implantada em 2002 que o departamento tomou a decisão separar a licenciatura do bacharelado e implantar a licenciatura no noturno. 
No período que estive no departamento, houve requisição e abertura de várias vagas e nós praticamente dobramos o número de professores, o que permitiu o oferecimento da licenciatura noturno, a abertura da implementação do programa de Pós-Graduação a partir de 2007, inicialmente com nível de mestrado e mais recentemente, o doutorado. Além disso, oferecemos várias turmas de graduação regulares fora de sede, em Parintins, São Gabriel da Cachoeira e Coari. Também participamos dos Programas Especiais de Formação de Docentes - PEFD e mais recentemente o PARFOR.

Vale lembrar que meu concurso foi para a vaga de humanas do Departamento, mas quando retornei do mestrado, tendo trabalhado com ferramentas de SIG na dissertação, o departamento tinha demanda na área de Cartografia e Sensoriamento Remoto. Demonstrei interesse em migrar para esta área, o que foi aprovado, passando a trabalhar com as disciplians técnicas.

\section{C: O senhor também foi chefe do departamento de Geografia. Quais foram os principais desafios e conquistas?}

G: Eu diria que foi um momento muito importante na história do Departamento. Estive na função de chefe de setembro de 2009 a agosto de 2011, momento em que foram intensos os debates no colegiado acerca das grades da graduação, tanto da Licenciatura quanto do Bacharelado. Naquela oportunidade conseguimos reestruturar a grade da licenciatura que entrou em vigor em 2011. Prometemos retomar a discussão acerca da grade do bacharelado em 2012, tarefa que não foi retomada até o momento presente.

\section{C: E enquanto coordenador do Programa de Pós-Graduação em Geografia - PPGeog - Geografia/UFAM?}

G: Ao concluir os dois anos de mandato como chefe do Departamento de Geografia, fui eleito coordenador do Programa de Pós-Graduação em Geografia - PPGGeog. Foi uma experiência riquíssima, e talvez a principal contribuição neste período foi a aprovação do Seminário de Projetos - prática que passamos a adotar desde então e que está em vigor atualmente. Também tivemos a oportunidade de tocar o Programa Nacional de Cooperação Acadêmica - PROCAD, no qual dois PPG já consolidados (PPG de geografia da UNESP de Presidente Prudente e o do IG/UFU - liderados respectivamente pelos professores Raul Borges Guimarães e Samuel do Carmo Lima) apoiaram o desenvolvimento do nosso PPG. Este projeto foi coordenado pelo professor José Aldemir de Oliveira. Apesar dos parcos recursos deste programa oferecido pela CAPES, foram muitos os momentos de debate em torno da Geografia da Saúde no Brasil e no mundo, com repercussão positiva para o nosso PPG.

O ponto culminante deste empreendimento foi a realização do $4^{\circ}$ Congresso Internacional de geografia da Saúde, realizado nas dependências da UFAM 
“A VIDA NÃO É FÁCIL, A MINHA TAMBÉM NÃO FOI. MAS VALEU ATÉ AQUI"

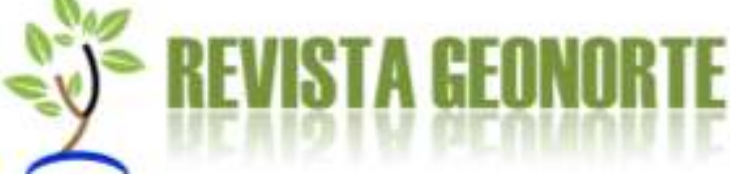

coordenado por nós do Núcleo de Estudos e Pesquisas das Cidades da Amazônia NEPECAB em 2014.

\section{C: As duas experiências anteriores ajudaram de alguma forma no seu trabalho} no INEP, enquanto avaliador institucional - atividade que realiza desde 2010 ?

G: Sim, principalmente o de coordenador da pós-graduação. Houve um tempo em que o Ministério da Educação - MEC envidou consideráveis esforços para a avaliação das Instituições de Ensino Superior - IES no Brasil e dos cursos de graduação. Tive a oportunidade de me envolver diretamente com avaliação das instituições. Fui membro de comissão de avaliação de instituições em diversos estados brasileiros, oportunidade para conhecer o funcionamento de IES pelo Brasil. Ao que parece este processo vem passando por profundas transformações. Desde o governo de Michel Temer não recebi novas designações para a composição de comissões de avaliação.

C: Do ponto de vista da participação estudantil e a relação professor-aluno, na sua opinião, quais devem ser as frentes de articulação e pautas que dependem dessa união e respeito para o avanço da ciência geográfica e do curso de Geografia no Amazonas?

G: Quando estava no departamento defendi, em diferentes momentos, a realização de assembleias entre professores e alunos do curso, com o propósito de (ouvindo os alunos) reconhecer pontos de melhorias que o Departamento deveria buscar implementar. Penso que professores e alunos devem sempre trabalhar na perspectiva de melhorar, revisar, atualizar o curso de graduação e de pósgraduação. O Centro Acadêmico de Geografia tem um papel importante na articulação dos alunos e destes com o departamento.

C: Observando um pouco mais sua atuação enquanto professor, as disciplinas correlatas à Cartografia e ao Sensoriamento Remoto, estiveram presentes tanto em sua formação profissional, quanto em sua grade de ensino. Os mapas são objetos fundamentais ao trabalho do Geógrafo, contudo, têm sido um dos principais desafios no ensino-aprendizagem em Geografia nas escolas, segundo algumas pesquisas. Também, percebe-se que os geógrafos têm perdido o protagonismo nesta área para as engenharias, por exemplo. Levando em consideração seus anos em sala de aula à frente das disciplinas, como o senhor analisa esta situação? Como os docentes e discentes podem reverter este quadro?

G: Os avanços na área das Geotecnologias são significativos desde o lançamento dos primeiros satélites de sensoriamento remoto e o surgimento dos SIG ferramentas importantíssimas para o reconhecimento das transformações sobre o 
território. Mas ao contrário, nós da Geografia temos aproveitado pouco este crescimento. Penso que um dos principais aspectos para esta realidade seja a forte influência da Geografia Crítica no pensamento geográfico brasileiro e a subvalorização dos dados como subsídios para a interpretação do espaço geográfico. Acresce-se a isso a pouca disposição de quem ingressa nos cursos de geografia para estudar aspectos mais técnicos relacionadas com Matemática e Física, necessários ao domínio destas tecnologias.

Devemos considerar o poder aquisitivo pouco favorável de muitos alunos, o que dificulta aquisição e convivência com os recursos computacionais necessários ao desenvolvimento das habilidades nesta área. Esses fatores somados tem levado a um pouco envolvimento dos estudantes de graduação em Geografia ao domínio dessas técnicas e tecnologias.

Penso que é necessário disponibilizar salas, laboratórios equipados com computadores para que os alunos de graduação convivam o máximo possível com essas tecnologias, aumentar a carga horária desses conteúdos e encorajar aqueles que dispõe de condições financeiras para a adquirir computadores pessoais para familiarizar com recursos de geoprocessamento.

C: O senhor também ministrou disciplinas relacionadas ao uso de Geotecnologias e Ensino, e esteve inserido neste contexto, durante os anos da pandemia de Covid-19. Como foram suas experiências de ensino e pesquisas durante a pandemia de Covid-19? Alguma sugestão para quem for trabalhar com o tema nos cursos de Geografia, especialmente no Amazonas?

G: Sim. Trabalhei Geotecnologias e Ensino de Geografia para turmas de licenciatura em Geografia. Ofereci a mesma disciplina duas vezes (no segundo semestre de 2020 primeiro de 2021 - finalizada em junho). Já havia oferecido ela várias vezes, mas a experiência de realizá-la remotamente foi muito interessante por alguns aspectos que talvez vale a pena destacar.

Primeiro, fiz uma sondagem para reconhecer as condições dos alunos para cursar uma disciplina que depende essencialmente de recursos computacionais e constatei que muitos dispunham apenas de celular para acompanhar o curso, o que já representava um desafio considerável. Segundo que, ao longo da disciplina, professor e alunos foram descobrindo como fazer, porque era algo inédito na nossa graduação e concluímos bem tanto na primeira quanto na segunda turma. Esta segunda experiência já foi um pouco mais fácil por conta da experiência anterior.

Penso que quem for ministrar essa disciplina precisa ter sensibilidade para reconhecer os desafios que determinados alunos enfrentam de duas naturezas: o domínio das ferramentas computacionais que serão necessários e a outra que é a disponibilidade e acesso a esses recursos para a realização das atividades programadas. 

AQUI"

\section{C: Poderia falar um pouco sobre o Sistema de Proteção da Amazônia - SIPAM? Como foi participar da fase inicial do SIPAM, e na sua percepção, qual deve ser o papel atual do instituto?}

G: O SIPAM foi (e até onde vai meu conhecimento) continua sendo uma grande decepção! Projetado para ser uma instituição com atuação abrangente sobre a Amazônia, dotado de recursos capazes de identificar e combater ações ilícitas na região, além de apoiar iniciativas adequadas de desenvolvimento humano e social, acabou desconfigurado por uma série de ingerências e de aspectos que vale a pena comentar.

Sem recursos humanos próprio, teve que iniciar as suas atividades com empresas terceirizadas, prestadoras de serviço, e a requisição de servidores de instituições federais, tais como das universidades. Inicialmente pode contar com equipes tecnicamente muito competentes, mas que tiveram os seus projetos impedidos ou até interrompidos (e resultados não valorizados) em função de interferências de lideranças políticas regionais e/ou principalmente a partir de Brasília. Os centros regionais de Manaus, Belém e Porto Velho não gozavam de autonomia para conduzir seus projetos e muitas vezes a decisão final de Brasília tinha forte interferência política, o que aniquilavam os resultados de trabalhos das equipes. À medida em que o tempo foi passando, os contratos com as empresas terceirizadas foram sendo encerrados. Buscou-se então a realização de concurso público que demorou para ser viabilizado e isso foi esvaziando a instituição.

Eu retornei à UFAM em abril de 2008. Inicialmente o SIPAM estava subordinado à Casa Civil da Presidência da República. Foi transferido para Ministério de Ciência e Tecnologia e depois para o Ministério da Defesa, o que mostra uma falta de identidade institucional. Pode-se dizer que uma das grandes dificuldades da instituição foi não encontrar um nicho próprio de atuação, visto que boa parte da sua expertise sombreava com outras instituições, tais como a Polícia Federal, o IBAMA e a Agência Brasileira de Inteligência. Por outro lado, sem ter poder de polícia e sem gozar de autonomia não dispunha de condições para tocar certos projetos.

Penso que a melhor contribuição que a instituição poderia dar à sociedade brasileira seria na manutenção de equipes competentes para o levantamento e tratamento de dados ambientais da Amazônia com vistas ao combate de ações ilícitas tais como o garimpo ilegal, extração ilegal de madeira, desmatamento entre outros. Mas para tanto precisaria contar com outras instituições capazes de, valorizando seu trabalho, planejar e executar ações de combate aos ilícitos.

C: O senhor atualmente é o lider do Núcleo de Estudos e Pesquisas das Cidades da Amazônia - NEPECAB. Poderia contar um pouco da sua relação e história com o grupo de pesquisa? E os professores que lá atuam, como 
“A VIDA NÃO É FÁCIL, A MINHA TAMBÉM NÃO FOI. MAS VALEU ATÉ AQUI"

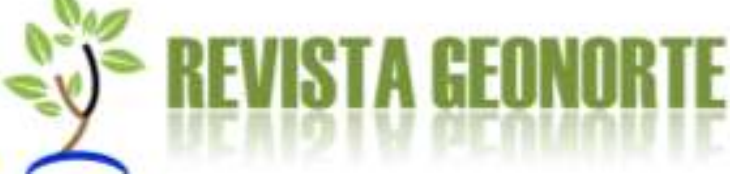

funciona o desenvolvimento de projetos e como foi trabalhar com eles ao longo destes anos?

G: O NEPECAB foi fundado em 1995. Quando o professor José Ademir de Oliveira retornou do doutorado teve iniciativa de criar um grupo de pesquisa e assim surgiu o então Grupo de Estudos e Pesquisas das Cidades da Amazônia Brasileira GEPECAB. Tive a honra de ser convidado pelo professor Aldemir para integrar o grupo desde a sua fundação. Um pouco mais à frente entraram as professoras Tatiana Schor e Paola Verri de Santana e decidimos mudar o nome dele para Núcleo de Estudos, ao invés de grupo. Nós conseguimos integrar com professores das federais de Roraima e do Mato Grosso. Em 2010 fizemos um workshop em comemoração aos 15 anos do Núcleo e tivemos a participação de vários professores, inclusive da professora Maria Laura da Silveira, da Universidade de São Paulo.

O já citado PROCAD, voltado para Geografia da Saúde, trouxe bons resultados e permitiu que alunos de pós-graduação do nosso programa fosse cursar disciplinas no Programa de Pós-Graduação na Geografia IG/UFU e na UNESP Presidente Prudente, assim como nós também recebemos alunos vindo de lá para desenvolver parte dos seus trabalhos de pós-graduação aqui. O marco mais importante desse projeto foi à participação nos congressos internacionais de Geografia da Saúde e sediar o $4^{\circ}$ Congresso Internacional de Geografia da Saúde foi realizada aqui em Manaus as dependências da UFAM um ano de 2014 sob a coordenação do NEPECAB, tendo o professor José Aldemir como o coordenador-geral do evento. Contamos com a participação de pesquisadores vindos do México, da Argentina, Moçambique, França e Portugal.

Um aspecto importante do NEPECAB é o empenho de todos os professores com orientação de projetos de iniciação científica. Ao longo destes mais de 20 anos de atuação, tivemos alunos que começaram com pesquisa na iniciação científica, seguiram para o mestrado e doutorado. Lamentavelmente perdemos o nosso líder em 2019 e em seguida veio a pandemia. Tivemos que ficar por esse período afastados das dependências do núcleo. Estamos com expectativa de retornar as nossas atividades no início de 2022. Esperamos voltar com toda disposição recuperar o que terá sido avariado e colocar os projetos em andamento novamente para dar continuidade a este núcleo que já tem uma grande contribuição dada à Geografia da Amazônia e muito ainda a colaborar.

C: A pauta da Mobilidade e do Transporte Urbano esteve presente em boa parte de sua atuação enquanto pesquisador, orientador e cidadão. Como o senhor vê o desenvolvimento de projetos relacionados ao desenvolvimento de projetos de humanização das cidades e da mobilidade urbana? Como o senhor entende que a temática seja tratada? Quais suas recomendações aos gestores públicos, planejadores urbanos e a quem se interessa pelo tema? 
G: Uma olhada superficial sobre a história econômica recente mostra que o Estado tem variado entre comportar-se de modo mais intervencionista e por assim dizer, paternalista (preocupado em fomentar a economia, gerar empregos, promover o desenvolvimento econômico da sociedade) e em outros momentos uma atuação mais liberal, deixando que as atividades econômicas sejam conduzidas prioritariamente pela iniciativa privada. Neste momento advoga-se pela redução do estado, enxugar a máquina administrativa. A partir da década de 1980 os países do terceiro mundo passaram a conviver com a intervenção do Fundo Monetário Internacional (FMI) apregoando a agenda neoliberal de desestatização e redução do estado. Uma boa parte das empresas estatais foram repassadas à iniciativa privada através das privatizações. Penso que hoje vivemos as consequências dessa política neoliberal. $E$ isso tem a ver com a pergunta em questão - a gestão humanizada das cidades.

Recentemente entramos na era da economia criativa e compartilhada, boas ideias sendo compartilhadas o tempo todo. É o caso de cidade para as pessoas, mais humanas - cidades que promovem a inclusão das pessoas, de todos os níveis sociais. Mas, lincando com a abordagem inicial, é preciso observar que o estado perdeu muito da sua capacidade de intervenção e os recursos estão mais reduzidos. Aqui falo principalmente da redução da máquina pública, dos recursos humanos. A título de exemplo sobre a mobilidade urbana podemos destacar que no início da década de 1980, quando a prefeitura de Manaus criou a Empresa Municipal de Transporte Urbano - EMTU, havia mais de 400 fiscais de rua para atuação na cidade de Manaus para fiscalizar a prestação do serviço transporte coletivo, fiscalização de táxi entre outras. Atualmente este número deve estar reduzido a $10 \%$ do que foi. Neste exemplo vemos que a redução do estado foi brutal, com forte impacto sobre a sua capacidade de prestar o serviço de fiscalização. Isto mostra que, por melhor que sejam as ideias, as propostas, elas têm esbarrado na implementação. Então, podemos ter uma cidade rica em ideias, mas de pouca capacidade de implementação. Assim, penso que é preciso recuperar a capacidade de agir do estado. Agir para implementar, para fiscalizar, para estimular, para promover. Sem isso a ideia de cidades mais humanizadas não sairá do papel.

\section{C: Qual o papel central da Geografia na temática da Mobilidade Urbana? Como podemos contribuir e assumir um certo protagonismo em uma área pouco difundida na ciência geográfica?}

G: A Geografia pode contribuir muito para superar desafios da mobilidade urbana. Mas para isto é preciso ser ouvida, é preciso haver abertura para valorizar os conhecimentos e contribuições da Geografia. A gestão municipal não tem sido muito receptiva às contribuições dos geógrafos. É comum o comando da mobilidade urbana ser entregue a pessoas ligadas à segurança pública, parecendo ser uma questão de autoridade, não de gestão. O município de Manaus é um belo exemplo disso. Apesar dos esforços para ampliar o debate em torno das questões da mobilidade urbana, poucos foram os avanços, emperrado por diretores e técnicos 
“A VIDA NÃO É FÁCIL, A MINHA TAMBÉM NÃO FOI. MAS VALEU ATÉ AQUI"

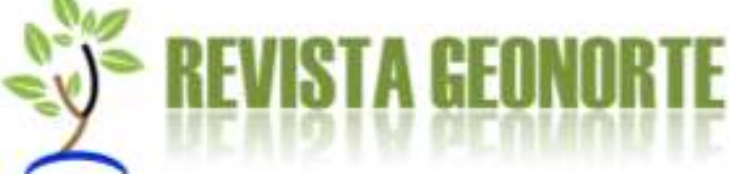

fechados ao diálogo, autossuficientes e ignorante às questões sociais que afligem parte da população no seu ir e vir diário.

\section{C: Em relação a evolução e novas perspectivas para a Geografia, existe alguma reflexão que tenha feito nos últimos anos e que deseja expor?}

G: Quero falar da atuação do geógrafo enquanto professor de geografia - maior mercado de atuação desse profissional. Penso que a pandemia trouxe grandes desafios para academia como um todo, em especial para as licenciaturas. Ao mesmo tempo em que apresentou desafios, trouxe também oportunidades, novas janelas de aprendizado e de experiências. Uma nova realidade, especialmente dos recursos utilizados durante a pandemia para as aulas à distância e que devem continuar de uma forma ou de outra daqui para frente.

Penso que é preciso estar atento e investir pesado nessa nova frente que passa, obrigatoriamente, pelo domínio dos recursos das tecnologias computacionais. $O$ diálogo de aprendizado entre professores estudantes das novas gerações passará, obrigatoriamente, por linguagens de geotecnologias. Nossos cursos de graduação farão a revisão necessária da sua atuação para tornar contemporânea a formação que é oferecida aos novos estudantes? Ou permaneceremos apegados a antigas práticas que pouco tem a ver com a nova realidade?

\section{C: Como considerações finais, pode nos contar um pouco sobre sua atuação acadêmica no futuro? Fica em aberto para as palavras de considerações finais.}

G: Gostaria de agradecer o convite da Revista Geonorte e a oportunidade de, fazendo uma retrospectiva da minha vida profissional, destacar aspectos que foram marcantes e que pode até servir de estímulo à outras pessoas. Como para a maioria delas a vida não é fácil, a minha também não foi, mas valeu até aqui. Valeu ter escolhido Geografia: não fiquei rico, mas também não passei fome por tê-la abraçado. Valeu teria escolhido a graduação em universidade pública como espaço de trabalho. Valeu ter conhecido alunos fantásticos que vieram trabalhar comigo e que hoje são profissionais competentes e com um futuro brilhante pela frente. Talvez eu abrace outra frente de atuação, menos exigente. Ocupar-se sem trabalhar muito, sem se prender a compromissos diários. Talvez seja o melhor jeito de levar a vida daqui para frente. Mas tudo isso ainda está em aberto. Afinal aposentadoria acabou de acontecer. Forte abraço!

Recebido em 26/12/2021

Aceito em 30/12/2021

REVISTA GEONORTE, V.12, N.40, p.114-127, 2021.

DOI: 10.21170/geonorte.2021.V.12.N.40.114.127

(ISSN 2237 - 1419) 